\title{
Dossiê
}

\section{Do desembarque do navio \\ ao embarque na canoa: \\ Gioconda Mussolini, 1886-1938}

Andrea Ciacchi

Universidade Federal da Integração Latino-Americana

Para a professora

Núncia Santoro de Constantino

in memoriam

RESUMO: O objetivo principal deste trabalho é a reconstrução de um aspecto específico da trajetória biográfica e intelectual de Gioconda Mussolini, aluna, assistente e professora, sucessivamente, na Faculdade de Filosofia, Ciências e Letras da Universidade de São Paulo de 1935 a 1969: o seu percurso escolar, da infância à licenciatura na FFCL. Proponho, no entanto, ir ainda mais longe, no tempo e no espaço, para incluir nesta trajetória a chegada da Itália ao Brasil da sua família paterna, em 1886, e a sua experiência escolar, na cidade de São Paulo, nos anos Vinte e Trinta do século passado. A hipótese é que esse percurso é determinado em grande medida pelo seu pertencimento a uma parcela peculiar da experiência ítalo-paulista no começo do século XX, por um lado, e, por outro, que ele determina o seu encaminhamento para as ciências sociais e para a Antropologia.

PALAVRAS-CHAVE: Gioconda Mussolini, Antropologia brasileira, trajetórias intelectuais, Instituto de Educação "Caetano de Campos", Faculdade de Filosofia, Ciências e Letras da Universidade de São Paulo, Emigração italiana em São Paulo. 
A antropóloga Gioconda Mussolini não é uma anônima, mas quase. Em 2013 seriam comemorados os cem anos do seu nascimento, em curiosa coincidência com o centenário do seu colega, chefe, orientador, o prof. Egon Schaden. Infelizmente, porém, apesar de algumas publicações relativamente recentes (Ciacchi, 2007a, 2007b e 2015), a sua trajetória e, portanto, a compreensão completa do lugar que ela ocupou na história da antropologia brasileira, ainda está a merecer uma abordagem mais completa.

Gioconda Mussolini nasceu em 15 de novembro de 1913, em São Paulo, no bairro do Bom Retiro ${ }^{1}$. Sua história, no entanto, começa bem antes, e muito longe dali.

No dia 7 de abril de 1886, desembarcaram do navio Washington, no porto de Santos, Antonio (45 anos), Silvio (23 anos) e Cesare (11 anos) Mussolini. São os únicos italianos com esse sobrenome a terem chegado a esse porto no século XIX, segundo consta no "Livro de Registro de Imigrantes da Hospedaria de São Paulo"2. O cruzamento das informações contidas nos documentos sobre imigração vêneta, nas lembranças familiares e nas datas de nascimento e morte dos Mussolini sepultados no Cemitério São Paulo, em Pinheiros, permitiu saber que o avô paterno de Gioconda chamava-se Silvio Mussolini, nascido em Pádua (ou na província de Pádua) em 1860. Ele casou-se com Carolina Peretti Mussolini, nascida na província de Rovigo, em 1866. Em 1886, em Veneza, onde o casal passara a residir, nasceu Umberto Mussolini, o pai de Gioconda.

No mesmo ano de 1886, Silvio, com seu pai (e bisavô de Gioconda) Antonio (nascido em 1841) e o irmão mais novo Cesare (nascido em 1875) vieram ao Brasil. Em 1888, vieram Carolina e o pequeno Umberto, então com dois anos de idade.

A emigração italiana - e, mais especificamente, vêneta - para o Brasil é tema de inúmeras obras historiográficas e sociológicas, como se sabe. Aqui, cabe apenas lembrar que as províncias de onde provavelmente vieram os nossos Mussolini (Pádua, Rovigo, Veneza) pertencem à região do Vêneto caracterizada por planícies, ocupadas, na segunda metade do século XIX, por "grandes propriedades, já com caráter capitalista" (Alvim, 1986: 28), mas que, nesse período, passaram por grave crise, a "grande depressão", que viabilizou a passagem para o capitalismo monopolista. Nesse contexto, a proletarização do pequeno produtor agrícola "tornou-se sinônimo de expulsão" (Idem: 34) e de emigração. O ano da chegada dos Mussolini corresponde ao começo da "segunda fase" da grande imigração italiana. Na formulação de Zuleika Alvim (Idem: 34), entre 1885 e 1902, “consolida-se [no Estado de São Paulo] nova facção econômica no poder - os fazendeiros do Oeste -, enquanto o mercado de trabalho se apóia de fato na mão-de-obra livre, definindo-se, então, uma política imigratória, basicamente calcada no imigrante italiano". Dos dois lados do 
Atlântico, portanto, injunções e interesses econômicos distintos, mas articulados e convergentes, fizeram com que os números acima mencionados se tornassem tão vultosos e socialmente significativos.

Estabelecido na cidade de São Paulo (mas não sabemos em que região), acompanhado por seu pai, Antonio, sua mulher, Carolina, e seu filho, Umberto, Silvio Mussolini abriu uma "fábrica de licores", como relata a irmã de Gioconda, Dona Ariclé. Essas atividades industriais, ainda que não documentadas, devem ter permitido uma rápida ascensão social dessa família de imigrantes, que, diferentemente da grande maioria dos seus conterrâneos vênetos, não completou sua viagem se dirigindo para as fazendas de café no interior do Estado.

Essa vertente urbana da emigração italiana em São Paulo, embora muito menos estudada que aquela que se dirigiu de imediato para os centros cafeeiros do interior, é muito relevante. Segundo Angelo Trento (1989: 127), um historiador italiano especialista em emigração italiana,

O emprego urbano dos italianos começa praticamente com as primeiras correntes migratórias, estimulado pelas transformações econômicas pelas quais o Brasil passa no período de maior afluxo. Ao chegarem num momento de transição, isto é, quando a escravidão entra em crise e se recorre ao trabalho livre, os imigrantes conseguem inserir-se num contexto urbano ainda magmático, que oferece possibilidades de empregos em fase de gestação e de definição, e, portanto, ainda não aproveitadas pelos poucos trabalhadores urbanos locais.

Impossível não lembrar que no ano de chegada dos primeiros Mussolini, 1886, o Brasil ainda é um império, e boa parte da sua vida econômica, social e cultural se encontra estruturada a partir do regime escravocrata. Nesse mesmo ano, a população da cidade de São Paulo não passava de 47 mil pessoas (Hutter, 1972: 77). Na síntese de Franco Cenni (1975: 208), "naquele tempo estava se forjando o futuro do Brasil, com a abolição e a proclamação da República, grandes reformas que teriam como conseqüência uma modificação radical em todo o sistema econômico da Nação".

Há, de fato, numerosos registros de imigrantes que, apesar de destinados às fazendas de café, resolveram ficar na capital paulista, sobretudo nas últimas décadas de 1880 (Idem: 93). Assim, teria sido “incalculável”, nas cidades paulistas, sobretudo na Capital, a quantidade de "tendas de sapataria, marcenarias, fábricas de massas, de graxa, de óleos, de tintas de escrever, fundições, tinturarias, fábricas de calçados, manufaturas de 
roupas e chapéus que funcionam em estalagens, em fundos de armazéns, em resumo: em lugares que o público não vê" (Cenni, 1975: 203). Muito rapidamente, como mostra Edgar Carone, na estratificação social da Primeira República se formou mesmo uma "classe média intermediária" formada por "imigrantes [...] portugueses, italianos, sírios, [que] imigraram diretamente para as cidades ou abandonam o campo pelo comércio" (Carone, 1972: 178). Para perfazer esse panorama, Richard Morse desenha uma espécie de cadeia de ascensão social que parte do pequeno mascate, cujo sonho teria sido o de "estabelecer-se com loja ou fábrica numa cidade, idealmente, São Paulo” (Morse, 1970: 240).

O mesmo adjetivo é usado, novamente, pelo mesmo observador contemporâneo, Antônio Francisco Bandeira Junior: “É incalculável o número de pequenas marcenarias em que trabalha um só homem. [...] fábricas de bebidas e de massas, vulgarmente conhecidas por "macarrão"' (Cenni, 1975: 203-204). Lucy Maffei Hutter (1972: 15) também relata que “a pequena indústria [...] estava, em princípios deste século, quase que inteiramente nas mãos dos italianos, os quais implantaram fábricas de cervejas, de licores, de gêneros alimentícios etc.".

É mais cuidadoso o olhar de José de Souza Martins (1981: 253), que, alertando para o perigo de se reproduzirem as representações ideológicas da época, calcadas na figura do self-made man (casos como os das indústrias Matarazzo ou da família Crespi, abordados pelo autor, permitem quebrar esse paradigma). Martins também lembra que "as indústrias de imigrantes italianos eram predominantemente familiares e sobretudo de família nuclear” e que, "ao contrário dos descendentes de alemães, que preferiam a indústria mecânica e metalúrgica, os italianos preferiam nessa época a indústria de bens de consumo, principalmente tecidos, chapéus, calçados e alimentos" (Idem: 253-254).

Infelizmente, as lembranças familiares dos descendentes de Silvio Mussolini não permitem vislumbrar mais que isso: como, onde e quando ele chegou a abrir a sua "fábrica de licores" e como e durante quanto tempo ela funcionou ainda não foi possível saber. Seja como for, em pouquíssimos anos, os Mussolini tornam-se paulistanos, pertencentes a uma incipiente, mas determinada, classe média urbana. Todos, aliás, logo se naturalizam brasileiros. Essa última informação, apresentada por Dona Ariclé, que me parece funcionar como mito de formação de uma brasilidade específica, enquanto precoce e bem sucedida, liga-se também à política da recém-instituída República Brasileira: um decreto de 14 de dezembro de 1889, considerando o "inolvidável acontecimento do dia 15 de novembro de 1889”, determinava que todos os estrangeiros residentes no Brasil no dia da proclamação 
da República seriam automaticamente considerados cidadãos brasileiros, salvo declaração em contrário no prazo de seis meses (Hutter, 1972: 135).

As possibilidades de capitalização econômica, social e cultural desse núcleo inicial dos Mussolini são, como se disse, de dificílima visualização. Mesmo assim, sabemos que, na década de Noventa, o pequeno Umberto se alfabetizou com uma maestra, uma professora particular italiana, e, mais tarde, estudou contabilidade (também num curso particular) e trabalhou um tempo como contador. Esteve empregado, nessa qualidade, numa grande empresa industrial de chocolate e balas do começo do século, no bairro do Bom Retiro. Talvez a experiência nessa firma, além do exemplo paterno, tenha feito surgir o desejo de ter o seu próprio negócio. Mais tarde, de fato, Umberto abriria uma fábrica de doces italianos, onde produzia panettone, torrone, balas e outras guloseimas, no Brás. Silvio e Umberto, portanto, devem ter pertencido àquele setor dos contingentes de imigrantes italianos que protagonizaram uma ascensão econômica e social considerável. O panorama é bem sintetizado por Warren Dean (1975: 271): os industriais imigrados “compreendiam as [...] preferências [dos seus conterrâneos] em matéria de alimentação, vestuário e habitação, e instalaram máquinas para produzir os biscoitos, a pasta, a cerveja, os óleos de cozinha [..] e outros bens que acabaram sendo aceitos também pelas classes inferiores nativas". O sobrenome Mussolini não aparece entre as dezenas de sobrenomes italianos citados pelos numerosos repertórios e reconstruções historiográficas voltadas para o esclarecimento da posição dos imigrantes na industrialização paulista e paulistana entre 1880 e $1930^{3}$. Mas, se ele não iguala nem se aproxima - em termos de capital econômico e, muito menos, simbólico - a sobrenomes como Matarazzo, Crespi ou Siciliano, mesmo assim Silvio e Umberto devem ter logrado a construção de um espaço nos interstícios da classe média da capital, como, inclusive, testemunham alguns dos endereços onde passariam a residir.

Umberto - diz Dona Ariclé - gostava muito de dançar e, num baile de carnaval, conheceu Adalgisa Vieiga (nascida em 1889, filha de pai português e mãe brasileira), com quem casaria, em 1907. Depois do casamento, Umberto e Adalgisa fixariam residência nos Campos Elísios, nas proximidades da Estrada de Ferro Sorocabana - um bairro de alto padrão, onde também morava uma parte da elite paulistana e onde, em 1911, se instalaria a residência oficial do presidente do Estado. Nesse bairro, mas numa rua não lembrada por Dona Ariclé, nasceram as duas primeiras filhas do casal: Norma (em 1908) e Aida (em 1910), assim como Silvio, que nasceu em 1911 e morreu com menos de dois anos de idade. Em 1912, a família Mussolini se mudou para uma casa maior, na Rua Doutor Rodrigo de 
Barros, 41, no Bom Retiro. Nessa casa, hoje derrubada, nasceram Gioconda (em 1913), e, entre 1915 e 1928, seus sete irmãos (apenas quatro irmãs sobreviveram). Em 1929, a família, a essa altura composta pelo casal, as sete filhas e o único menino, Ernani (que morreria, porém, em 1935), muda-se para uma casa na Rua dos Bandeirantes, a poucos metros da Dr. Rodrigo de Barros, da qual é praticamente a continuação, do outro lado da Av. Tiradentes, ainda no Bom Retiro.

No total, os Mussolini moraram no Bom Retiro durante vinte e dois anos, entre 1912 e 1934. Nesse período, eles e os demais moradores do bairro e da cidade passaram pelos efeitos da I Guerra Mundial, da gripe espanhola de 1918, das "revoluções" de 1924 e de 1932. A baliza de 1934, último ano de residência no Bom Retiro, marcará também o ingresso de Gioconda na faculdade.

É oportuno lembrar que o Bom Retiro, hoje muito identificado com a comunidade judaica de São Paulo, foi, nas primeiras quatro décadas do século Xx, predominantemente ocupado por famílias vênetas e de descendentes de vênetos, após pouco mais de vinte anos de "domínio" português, no final do século XIX.

Em 1920, Gioconda iniciou o curso primário (antes mesmo de completar sete anos de idade) no Colégio Santa Inês, na Rua Três Rios, no Bom Retiro, a poucos minutos de caminhada da casa da Rua Doutor Rodrigo de Barros. Lá, com as irmãs francesas (salesianas), Gioconda começou o estudo da língua francesa, que lhe seria tão útil, mais tarde, na interação com os professores da Faculdade de Filosofia. Em 1922, após dois anos de estudo com as freiras do Santa Inês, Adalgisa e Umberto colocam a filha numa escola pública, o Grupo Escolar Regente Feijó, na Av. Tiradentes, 90, também no Bom Retiro, ainda mais próximo da residência dela, com vista para o Jardim da Luz.

Parece significativo o fato de a instrução da pequena Gioconda não ter passado pela "miríade de escolas primárias que surgiam e desapareciam em ritmo impressionante" (Trento, 1989: 178), abertas e administradas por imigrantes; nem, mais tarde, pelo Istituto Medio Dante Alighieri, mais conhecido, ainda hoje, como Colégio Dante Alighieri, inaugurado em 1911 e dirigido, inicialmente, pelo bem sucedido empresário italiano Rodolfo Crespi. A opção dos pais de Gioconda pelo ensino público, depois de dois anos no colégio salesiano, não deve ser relacionada apenas a uma injunção econômica, pois o prestígio das instituições que a menina frequentou sucessivamente muniu-a de, como será evidenciado já no final da adolescência, uma excelente formação. Também devem ser levados em contas aspectos prosaicos que, muito provavelmente, orientaram as escolhas dos pais: no final da década de 1910, o Colégio Santa Inês era o único instituto de ensino 
do Bom Retiro, bairro onde residia a família. Assim que abriu um Grupo Escolar, público, nas vizinhanças (o Regente Feijó, a apenas 900 metros de casa), Gioconda foi logo matriculada nele.

Gioconda concluiria o primário na Escola Modelo do Brás, em 1926 . Esta escolha já apontava para uma vocação voltada para o magistério:

Em São Paulo, a difusão dos ideais anarquistas nos meios operários está na base da criação de duas escolas, uma no bairro do Belenzinho, em 1912 e outra no Brás, em 1918, que têm como modelo a Escola Moderna, fundada em 1901 pelo educador espanhol Francisco Ferrer y Guardia (1859-1909). Nesses bairros - com grande concentração operária e imigrante, e um número significativo de fábricas e oficinas - funcionam, desde o fim do século XIX, algumas escolas modelos, pensadas como laboratórios para formação de professores. Como, por exemplo, a Escola Modelo do Brás, inaugurada em 1898, em edifício projetado por Ramos de Azevedo. As Escolas Profissionais Feminina e Masculina do Brás são fundadas no interior desse processo de difusão de estabelecimentos de ensino para os trabalhadores e seus filhos na Primeira República. Além da capacitação técnica e profissional, afinadas com o ideário modernizador de uma sociedade que assiste aos primeiros passos de seu processo industrial, essas escolas apostam também na função moralizadora da educação voltada para o trabalho. Além de bons trabalhadores, e da valorização do trabalho manual em um país recém-saído da escravidão, deve-se formar "bons cidadãos". Os cursos, que duram cerca de três anos, são elaborados com base em aulas teóricas - português, geografia, aritmética etc. e práticas, realizadas nas oficinas e ateliês. $\mathrm{O}$ desenho constitui o núcleo central do currículo, habilitando o artesão e operário para a execução de projetos e planos. As aulas de desenhos garantem ainda a "educação pela correção da visão e firmeza da observação", articulando de modo exemplar habilitação técnica-especializada e formação moral ${ }^{5}$.

A história dessa escola é tortuosa, mas permite acompanhar a trajetória escolar de Gioconda: ou seja, permite visualizar o fato de que, na passagem do curso primário para o ensino secundário (Curso Complementar da Escola Normal e Escola Normal, de 1927 a 1932, como veremos a seguir), ela não saiu do mesmo prédio da rua Visconde de Abaeté, 154, no Brás, agora a cerca de meia hora de caminhada da casa dos Mussolini no Bom Retiro. Vamos ouvi-la na versão do Centro de Referência em Educação Mário Covas:

O Terceiro Grupo Escolar do Braz, anteriormente Seção Feminina do Grupo Escolar do Braz, foi criado por decreto de 8 de agosto de 1898, e [...] instalado no dia 11 de agosto do mesmo ano. [...] Segundo o Anuário de Ensino de 1913, esse grupo escolar, então denominado de Terceiro Grupo Escolar Modelo do Braz, funcionando no mesmo edifício da Escola Normal do Braz, teve matriculados, naquele ano, 906 alunos, com freqüência média de 609. [...] 
Conforme Decreto de 02.12.1938, essa escola passou a chamar-se Grupo Escolar Rocca Dordal. Por ocasião da reestruturação da rede oficial de ensino do Estado de São Paulo, na gestão do Secretário de Estado dos Negócios da Educação, José Bonifácio Coutinho Nogueira, conforme Resolução nº 24 D, de 28.01.76, o GESC Rocca Dordal foi fundido com o Instituto de Educação Padre Anchieta, para constituir a Escola Estadual de $1^{\circ}$ e $2^{\circ}$ Graus "Padre Anchieta" [...]. A atual EE Padre Anchieta foi criada como Escola Normal do Braz, em 24.12.1912 e instalada em 31 de março de 1913 [...]. Posteriormente recebeu os nomes de Escola Normal Feminina da Capital, Escola Normal Padre Anchieta (1920), Escola Normal e Ginásio Estadual Padre Anchieta e Instituto de Educação Padre Anchieta. Um dos edifícios onde funciona a atual EE Padre Anchieta, na rua Visconde de Abaeté, 154, no Brás, foi construído em $1912^{6}$.

Dona Ariclé lembra que Gioconda sempre foi uma menina que gostava de ler e de estudar, desde a primeira infância. Pelos seus relatos, uma vez, quando ela tinha seis anos, foi acometida por sarampo e, evidentemente, ficou em casa, de cama, sem poder ir à escola. Mas, na hora do almoço, a mãe foi levar-lhe o prato e ela não estava no quarto. Depois de procurá-la por toda a parte, descobriu-se que havia se trocado e ido à escola! A avó foi à sua procura e ela lá estava. Sua professora comentou que havia estranhado o fato de Gioconda ter chegado despenteada à escola. Quando ela estava matriculada no colégio Santa Inês costumava estudar embaixo de uma laranjeira, no jardim de casa, onde havia um balanço. Certa noite, Gioconda foi encontrada pela mãe destrancando a porta da cozinha, dizendo que precisava ir estudar um ponto. A mãe, então, mandou que ela voltasse para a cama.

Em 1924, no começo da adolescência de Gioconda, São Paulo

tinha ainda os sons dos pregões dos ambulantes, dos apitos dos trens e dos sinos das igrejas. Pelas ruas de paralelepípedos ou macadame trafegavam indiscriminadamente bondes elétricos, automóveis, alguns velhos tílburis e ainda carroças de lixo puxadas por parelhas de mulas (Cohen, 2006: 22).

No meio daquele mesmo ano, a partir do dia 5 de julho, outros sons rasgariam a cidade. A "Revolução de 24" duraria vinte e três dias e atingiria São Paulo, sobretudo em forma de bombardeios aéreos, que golpearam duramente bairros como os Campos Elísios, a Mooca, o Brás, Perdizes. A vida cotidiana dos moradores desses e de outros bairros da cidade foi muito afetada, evidentemente. A região onde moraram Umberto e Adalgisa, pela sua proximidade do palácio do governo, foi uma das primeiras a receber as granadas dos rebeldes. A defesa dessa área, por parte dos legalistas, levou o conflito para todos os 
bairros circunvizinhos, inclusive a Luz e o Bom Retiro, onde os Mussolini moravam já havia doze anos, com seus primeiros sete filhos, que estudavam nas redondezas. As trincheiras que se formavam eram defendidas "por metralhadoras, pistolas e granadas, dirigidas a esmo" (Idem: 34). Pior estava a situação na Avenida Tiradentes: a poucos metros do Grupo Escolar onde estudava Gioconda, surgia o Quartel do $4^{\circ}$ Batalhão de Infantaria, um dos principais alvos estratégicos dos revolucionários. Ali em frente ficava, então, a Escola Politécnica, a uma quadra da Rua Dr. Rodrigo de Barros: foi ela que sofreu as piores consequências. "Incêndios, saques e tiroteios intensos [...] transformaram a vida dos cidadãos em um verdadeiro inferno" (Idem). O testemunho de alguém que, mais tarde, se tornaria muito próximo de Gioconda - o escritor Paulo Duarte - é famoso: "as granadas caíam a esmo, ora aqui ora acolá [...] sem ponto certo. O bombardeio durava dias e noites sem cessar; a Santa Casa se enchia de mulheres e crianças, os cemitérios pejavam-se de cadáveres e as fileiras revolucionárias não perdiam um só homem" (apud Ibidem: 81). Passou...

Em 1927 e 1928 Gioconda ingressa no ensino secundário, frequentando o Curso Complementar da Escola Normal Padre Anchieta, ainda na Rua Visconde de Abaeté, 154, no Brás, e, logo em seguida, no mesmo endereço, a própria Escola Normal, onde, em 1932, portanto aos dezenove anos de idade, se formaria como "professora normalista". Na Padre Anchieta teve pelo menos um mestre ilustre, Antonio Ferreira de Almeida Júnior (docente de Biologia e Higiene), que se tornaria, em duas oportunidades, "chefe", ainda que distante, imaginamos, de Gioconda: entre 1936 e 1938, foi Diretor de Ensino da Secretaria da Educação do Estado de São Paulo, e entre 1945 e 1946, foi Secretário da Educação e Saúde Pública (Gandini, 2010).

É necessário lembrar que na década de Vinte, apenas uma minoria dos meninos e, mais ainda, das meninas, no Brasil, era encaminhada para o ensino secundário:

A escassez de estabelecimentos define, é certo, o caráter altamente seletivo do ensino secundário. [...] Taxas, selos e contribuições concorrem para que as escolas secundárias - públicas e particulares -, além de reduzidas em número, sejam instituições pagas e, mais do que isto, caras. [...] Dada a situação de ordem econômica e social que, assim, se configura, são os jovens afortunados que se beneficiam do ensinos secundário. [...] Nessas condições, pode-se dizer que o ensino secundário brasileiro, encaminhando para os cursos superiores, e conseqüentemente para as carreiras e profissões de prestígio, não é senão um instrumento de manutenção do status social elevado e de ascensão a este status (Nagle, 1974: 146-147). 
A Reforma Escolar promulgada em 1925, portanto dois anos antes de Gioconda ingressar no Curso Complementar da Escola Normal, determinara que o ensino secundário passasse de cinco para seis anos. Assim, Gioconda entra no Curso Complementar em 1927 e sai formada como professora normalista em 1932. Essas transformações, ainda segundo Jorge Nagle, atingem sobretudo a Escola Normal. Nessa esfera,

os cursos complementares [como o que Gioconda frequentou em 1927 e 1928] tiveram uma importância que não é demais acentuar: de um lado, representavam um aprofundamento e desenvolvimento do programa escolar primário; de outro, permitiam que a escolarização de nível primário avançasse pelo nível médio, ampliando o conteúdo de modo a se aproximar do da escola secundária. (Idem: 219)

“Aliás, a Escola Normal foi, durante longos anos, o meio de que se serviam as moças para adquirirem cultura; eram poucas as que se matriculavam, com o intuito de fazer carreira no professorado" (Americano, 2004: 374-375). Além disso, a partir dos anos Trinta,

o ingresso das mulheres nas escolas normais, consideravelmente superior à dos homens desde o início da República, torna-se cada vez mais pronunciado, evidenciando a presença majoritária do sexo feminino no magistério primário. Em 1940, nas escolas de ensino primário havia 17.961 professores; destes, 16.322 eram mulheres. É interessante observar que a entrada das mulheres para o ensino, iniciada no final dos oitocentos, coincide com o aumento do controle da educação por meio de programas e métodos pedagógicos, além da hierarquia de diretores e inspetores, enquanto autoridades masculinas suficientes, a exigir-lhes o exato "cumprimento do dever"".

Já em 1933, antes mesmo de completar vinte anos de idade, recém-formada como professora normalista, Gioconda ingressa oficialmente no quadro do ensino público paulista, nomeada para o Grupo Escolar de Pariquera-Assu, então distrito rural de Jacupiranga, no litoral sul do estado, e emancipado em 1953 - a pouco mais de 200 quilômetros de distância de São Paulo. Mas a permanência na região do baixo Vale do Ribeira será logo interrompida pela admissão, ainda em 1933, no Curso (bienal) de Aperfeiçoamento de professores primários que funcionava no prédio imponente do Instituto de Educação Caetano de Campos, na Praça da República, e que equivalia aos dois primeiros anos do Curso de Pedagogia da Faculdade de Filosofia da UsP.

É este o verdadeiro ponto de virada na carreira e na trajetória de Gioconda Mussolini. 
O Curso de Aperfeiçoamento fora criado pela reforma de Lourenço Filho, em 1931, para ser instalado no mesmo prédio da Praça, o Caetano de Campos. Ao frequentá-lo, Gioconda entra assim, pela primeira vez, no espaço educacional mais capitalizado, simbolicamente, de São Paulo. Mais que isso, pois na realidade, Lourenço Filho reformara a Escola Normal transformando-a em Instituto Pedagógico e, em 1933, no mesmo ano em que Gioconda se matricula nele, "Fernando de Azevedo ${ }^{8}$ introduziria novas remodelações no Instituto, tornando-o o 'Instituto de Educação' no qual foram incorporados a Escola de Professores, destinada à formação em nível superior de professores primários e secundários [...] e o Centro de Psicologia Aplicada [...]” (Fávero e Britto, 2002: 861). Em outras palavras, em 1933 iniciam-se os estudos superiores de Gioconda Mussolini, na primeira turma desse novo Instituto de Educação. É a primeira e única da frátria a dar esse passo, dado contemporaneamente aos primeiros passos do próprio ensino superior paulista, se atentarmos para o fato de que, até este ano, só existiam as Escolas “profissionais": Direito, Medicina e a Politécnica. A Escola Livre de Sociologia e Política também abria as suas atividades em 1933, e a USP, ao criar a Faculdade de Filosofia e ao reuni-la àquelas escolas e a este Instituto de Educação, só surgiria em 1934.

Sobre o Instituto de Educação da Universidade de São Paulo, suas rotinas, seus pressupostos ideológicos, suas esferas docentes e discentes, no período entre 1934 e $1938^{9}$, temos hoje o trabalho excelente e imprescindível de Olinda Evangelista (2002). Nele, inesperadamente, achei as pistas mais consistentes de algo que as lembranças dos amigos não alcançam e que a frieza burocrática dos documentos e da produção acadêmica não revela: o germe da vocação de Gioconda Mussolini para as Ciências Sociais e o seu concreto encaminhamento rumo a elas. Por isso, teremos que circular um pouquinho, agora, pelos corredores da escola da Praça, onde cruzaremos com alguns nomes que desempenharão um papel fundamental na formação de Gioconda e mesmo nos anos a seguir, e encontraremos, também, um conjunto de circunstâncias rapidamente transformadas em agências por parte da nossa jovem professora.

O IE foi estruturado por Fernando de Azevedo em dois níveis. Se ao primeiro pertenciam as "escolas de aplicação" (jardim de infância, escola primária e escola secundária), ao segundo correspondia o nível "superior" propriamente dito, com as cinco modalidades de cursos superiores: Formação de professores primários; Formação de professores secundários; Formação de diretores escolares; Formação de inspetores escolares; e o Curso de Aperfeiçoamento. Esses cursos tinham suas grades curriculares organizadas a partir da atuação de cinco Seções: Educação, Biologia Educacional, 
Psicologia Educacional, Sociologia Educacional e Prática de Ensino, cada uma responsável por uma série de disciplinas específicas dos vários currículos (Idem: 61). Entre elas, algumas constituíam uma novidade para Gioconda: História da Educação e Filosofia da Educação, na Primeira Seção (chefiada por Roldão Lopes de Barros (Idem: 111) ${ }^{10}$; Fisiologia e Higiene da Infância e da Adolescência, na Segunda Seção (que tinha Almeida Jr. como professor chefe); Psicologia da Criança e do Adolescente, Testes e Escalas, na Terceira Seção (chefiada por Noemy da Silveira Rudolfer ${ }^{11}$ ); Sociologia da Educação, Problemas Sociais da Educação, Problemas Sociais Contemporâneos e Investigações em Nosso Meio, oferecidas pela Seção de Sociologia Educacional (chefiada por Fernando de Azevedo) (Idem: 61-62).

Mas a estrutura do IE também contava com outras instâncias, além das Seções. No conjunto, vislumbra-se uma gama de ofertas pedagógicas e intelectuais que direcionariam, de forma decisiva, a orientação de Gioconda Mussolini. Professores, assistentes, disciplinas, espaços e oportunidades, nesse biênio 1933-1934, perfazem um pano de fundo que enxergo como ponto de partida para as escolhas que se concretizarão a partir do seu ingresso, em 1935, na Faculdade de Filosofia. De fato, foi na Praça, a partir da reforma de 1933, que se institucionalizariam aquelas "ciências fontes da educação" (Idem: 27) - História, Filosofia, Biologia, Psicologia e Sociologia - que, como veremos, concorrerão a definir a personalidade acadêmica da Gioconda, na sua maturidade.

Assim como aconteceria na Faculdade de Filosofia, o sistema de Cátedras também passará a predominar na praça, mas só a partir do Regulamento de 1935, quando as cinco Seções do IE tornam-se oito e mudam de denominação, tornando-se, aí sim, Cadeiras ou Cátedras (Idem: 110). Mas no período em que Gioconda esteve no Curso de Aperfeiçoamento, nas cinco Seções do Instituto ("Pedagógico" em 1933, e "de Educação", em 1934), agia um grande número de docentes, num modelo hierárquico composto de professores-chefes, assistentes, preparadores e subassistentes. Alguns deles já eram conhecidos de Gioconda, outros passarão a acompanhar-lhe a trajetória, ora de mais perto, ora de mais longe. Para melhor entender essas solidariedades e companhias, é necessário lembrar que o biênio em que ela frequenta o Curso de Aperfeiçoamento é atravessado por vários elementos de descontinuidade: em 1933 é regido ainda pelo Código de Educação "de" Fernando de Azevedo, ao passo que em 1934 o IE, passando a pertencer à recém-nascida Universidade de São Paulo, muda alguns dos seus princípios administrativos e organizacionais, além do próprio status dos seus membros. Para os professores, por exemplo, “o ano de 1933 funcionou como 'ritual de passagem’ para essa geração 
[de docentes], oferecendo as condições para que deixasse o talher de 'normalista' e assumisse, em 1934, o talher de professor universitário" (Idem: 123). Mas, paralela e simetricamente, o mesmo vale também para os alunos do Caetano de Campos desse mesmo período, sendo que para muitos destes a transição e o ritual de passagem se estenderiam até 1935, com o ingresso na Faculdade de Filosofia e a sua transformação em estudantes universitários.

Assim, além de Roldão Lopes de Barros, Almeida Jr., Noemy Rudolfer e Fernando de Azevedo, e do professor-chefe da Seção de Prática de Ensino, Antonio Firmino de Proença, Gioconda entra em contato com outros docentes, alguns dos quais pouco mais velhos que ela: alguns figurarão entre os seus colegas na FFCL, a partir de 1935, como Anita de Castilho e Marcondes Cabral (auxiliar no "Serviço de Psicologia Aplicada", dirigido por Noemy Rudolfer) e Zenith Mendes da Silveira (auxiliar no Laboratório de Psicologia). Além delas, devem ter desempenhado um papel importante na formação de Gioconda, entre outros, Milton Camargo Rodrigues, assistente de Roldão de Barros na primeira Seção, e Hermes Lima ${ }^{12}$ e Achiles Archêro Jr. ${ }^{13}$, na de Sociologia.

Mas uma posição fundamental seria ocupada por outra novidade do IE: os seus Laboratórios. Estes, ao lado da organização em Seções, constituíam a principal instância acadêmica da Praça. Através deles, aliás, o Instituto assumia para si a função de desenvolver e produzir conhecimento e não apenas a de repassá-lo.

O Laboratório de Psicologia, o mais antigo, dirigido por Noemy Rudolfer, contava com quatro seções: Mensuração, Estatística e Arquivo, Estudo dos Programas e Problemas Escolares, e Desenho e Representação, além de um Serviço de Orientação Profissional. Deve estar aí o embrião da solidez da formação psicológica de Gioconda que, como veremos, será sócia-fundadora da Sociedade de Psicologia de São Paulo (em 1945) e, quando professora de Antropologia na USP, levará aos seus alunos (inclusive para os de Psicologia, cujas turmas ela assumiu frequentemente) um vasto arsenal de conhecimentos dessa área, inclusive através dos autores ligados à escola norte-americana de cultura e personalidade. Segundo Olinda Evangelista, “os alunos do Curso de Administração Escolar e de Aperfeiçoamento de Professores Primários participavam de suas atividades e colaboravam para a verificação 'sobre a eficiência das classes selecionadas por testes psicológicos" (Idem: 85). Mais especificamente, e pensando na função deste laboratório na formação de Gioconda, é importante registrar que nele se buscava "conhecer os alunos através do estudo e questionário, de autobiografias, de palestras individuais, de trabalhos gráficos e manuais; do comportamento no grupo e discussão; das informações da educação sanitária; dos diretores e professores desses alunos; de visita domiciliar à família dos mesmos" 
(Ênfases minhas, Idem: 86). Em outras palavras, tudo indica que é com o pessoal deste Laboratório que Gioconda aprende os primeiros rudimentos de um tipo de investigação ao mesmo tempo experimental, multidisciplinar e de campo, muito próxima das práticas etnográficas que começaria a seguir cerca de dez anos depois, entre os pescadores da Ilha de São Sebastião.

O segundo Laboratório, o de Biologia Educacional, evidentemente dirigido por Almeida Jr., reunia o Centro de Puericultura e três seções: Técnica, Administrativa e Clínica. Mas, apesar da formação médica do seu chefe (na Faculdade de Medicina e Cirurgia de São Paulo, concluída em 1921), aqui também se desenvolvem "estudos de natureza social, em conjunto com a cadeira de Sociologia Educacional" (Idem: 83). Por outro lado, Gioconda deve ter compartilhado aí os princípios formadores de "uma concepção higienista de educação que atribuía ao Estado o dever de olhar com interesse o problema [assistencial da população carente]" e, ao mesmo tempo, com o "desígnio de transformar cada professora numa higienista" (Ênfases minhas, Idem: 84). É a partir, aliás, da colaboração entre esses dois laboratórios, e entre eles (e o IE, no seu conjunto) e outros órgãos municipais, que serão desenvolvidos, entre 1934 e 1938, uma série de inquéritos sociais na população de baixa renda da cidade de São Paulo, coordenados por sociólogos e estatísticos mais diretamente ligados à Escola Livre de Sociologia e Política: Bruno Rudolfer, Horace Davis e Samuel Lowrie. De pelo menos três, participa também Gioconda Mussolini. Os resultados desses inquéritos serão publicados na Revista do Arquivo Municipal, no período inicial das atividades do Departamento de Cultura do município, com Mário de Andrade e Paulo Duarte à sua frente.

Finalmente, embora não tenhamos maiores informações sobre as suas atividades e a sua rotina, basta o nome e a estrutura do terceiro laboratório para compreendermos a sua importância na formação de Gioconda: o Laboratório de Pesquisas Sociais e Educacionais, que contava com um Centro de Documentação Etnográfica e Social e com um Museu de Etnografia.

Seja como for, parece-me mais que verossímil que nesse biênio na Praça Gioconda Mussolini tenha tido acesso à "degustação" de um variado cardápio de novos sabores intelectuais, que lhe aguçaram um apetite a ser saciado, já a partir do ano seguinte, no curso de Ciências Sociais da Faculdade de Filosofia. Afinal, para uma moça em volta dos seus vinte anos de idade, nascida e criada no Bom Retiro, devem ter sido extraordinárias as experiências proporcionadas por um grupo de educadores também num momento decisivo e especial das suas atuações institucionais. Por sua vez, o lugar desse conjunto de práticas é 
também um lugar múltiplo: a Praça tinha posição e função centrais nesse quadrante da educação pública paulista. Nela convergiam elementos de um campo que me parece estar, ao mesmo tempo, em formação e em ponto de mutação, com a presença e a participação de médicos, higienistas, pedagogos, juristas, psicólogos, estatísticos, sociólogos. Tudo isso articulava-se numa rede institucional que, entre 1933 e 1935, incluiria também a Escola de Higiene e Saúde Pública ${ }^{14}$ (inclusive com os seus cursos de Educadores Sanitários, iniciados em 1919 e que continuariam a ser ministrados até 1962, formando um "exército" que também servirá nos mencionados inquéritos, sociais, alimentares ou sanitários que fossem), a Escola Livre de Sociologia e Política (com a sua missão de formar administradores para todas as áreas do "bom governo", paulista ou nacional), o Departamento de Cultura (com suas diversas subdivisões e a novidade das suas intenções multifocais e intersetoriais, entre arte e cidadania), e a própria Faculdade de Filosofia, Ciências e Letras. Estão nesse círculo as múltiplas e inebriantes atuações de Gioconda Mussolini nessa rede que constitui, evidentemente, mais um desdobramento da "comunhão paulista" (Cardoso, 1982). A mesma, justamente, que estava preparando o derradeiro passo para dar vida à Universidade de São Paulo. Gioconda, portanto, levada a percorrer esse campo desde 1933, e a equilibrar-se nessa rede, não chegará por acaso, em 1938, a ser escolhida por Paul Arbousse Bastide para ser sua assistente na Cadeira de Sociologia. O próprio Arbousse Bastide, além de outros nomes tantas vezes repetidos aqui, como Almeida Jr., Noemy da Silveira, Fernando de Azevedo, do lado da Praça, mas também, fora dela, Mário de Andrade, Bruno Rudolfer, Horace Davis, Samuel Lowrie, Claude Lévi-Strauss, estão nesse mesmo espaço.

Ao concluir o curso de aperfeiçoamento do Instituto de Educação, em 1934, na lembrança de Dona Ariclé, Gioconda é classificada como primeira da sua turma. Por conta deste brilhante desempenho, conta ainda a sua irmã, ela é nomeada para uma cadeira de professora efetiva no Grupo Escolar da Vila Prudente, na zona sudoeste da Capital. Mas, nos termos, mais burocráticos (e, provavelmente, mais acurados do ponto de vista cronológico), do Currículo de 1965, ela é "Removida [em 1936], por concurso de notas obtidas no diploma do Curso de Aperfeiçoamento supra-mencionado, para o Grupo Escolar de Vila Prudente [...], atualmente G.E. 'República de Paraguay"'. Na realidade, como veremos, as atividades de Gioconda como professora primária só se desenvolvem durante alguns meses de 1938. Em 1936, data da sua nomeação para a Escola da Vila Prudente, ela estava cursando o segundo ano de Ciências Sociais e Políticas, na Faculdade 
de Filosofia, onde fora admitida, justamente, como "professora primária comissionada", em 1935, ou seja, logo depois da conclusão do curso de aperfeiçoamento.

$\mathrm{Na}$ Faculdade de Filosofia, Ciências e Letras da Universidade de São Paulo, na sua Secção de Ciências Sociais e Políticas, Gioconda ingressara em 1935, na segunda turma da nova instituição. Essa história também é lembrada por Dona Ariclé:

Em 1934, uma amiga de infância de Gioconda, Carmen Kuchembuck, chegou para ela e disse que havia uma nova Faculdade de Filosofia, na cidade, e que estava abrindo vagas para normalistas. Gioconda e Carmen viraram madrugadas para estudar para o exame de admissão. Naquele carnaval de 1935, elas foram brincar a folia e, na volta, com um colchão colocado no escritório da casa da rua Pirapitingui, dormiram poucas horas, para voltar a estudar logo em seguida. Gioconda gostava de estudar, mas também de brincar o carnaval e dançar!

Dona Ariclé lembra ainda que para entrar na Faculdade, era obrigatório um exame em uma língua estrangeira, a ser escolhida entre francês, inglês e alemão. Gioconda escolhe a língua francesa, aprendida com as freiras do Santa Inês e aperfeiçoada na Escola Normal, e é classificada em segundo lugar. Em primeiro lugar é Mário Wagner Vieira da Cunha, também um normalista (Pinheiro Filho e Miceli, 2008), que faz o exame de alemão.

Entre pequenos acontecimentos familiares e privados e grandes movimentos sociais e culturais, o certo é que a trajetória da família Mussolini se desdobrou nas frestas do processo de construção da São Paulo moderna, "na confluência [...] [d]a abolição da escravatura (1888), [d]a instauração do regime republicano (1889) e [d]o surto de industrialização" (Mota, 2003: 255). Observada mais de perto, essa família, que preparava uma das suas filhas para ladrilhar um percurso rumo a uma posição de certo destaque, na esfera cultural e institucional, também pode ser flagrada no caminho que, ainda na formulação de Carlos Guilherme Mota $^{15}$, a levaria a

[...] um novo setor da sociedade que não pertencia à aristocracia rural ou urbana, mas também não era proletarizada. Era uma camada social intermediária, com frações sociais de várias origens, desde a pequena nobreza decadente, profissionais de vários ramos do comércio, funcionários de lojas, banqueteiros e cozinheiras da alta sociedade, alfaiates e chapeleiros, professores e assim por diante (Idem: 256-257).

Ao longo das cinco décadas que intercorrem entre a chegada de Silvio Mussolini da Itália (1886) e o ingresso da sua neta, Gioconda, na faculdade de Filosofia da USP (1935), a cidade de São Paulo muda o seu rosto. Os primeiros bondes elétricos, as primeiras opções de lazer 
doméstico (Dona Ariclé, conta com orgulho que a família Mussolini, quando residia na Rua Dr. Rodrigo de Barros, foi a primeira do bairro a possuir rádio, vitrola e... enceradeira!), a inauguração de novos teatros, a Semana de Arte Moderna, os primeiros clubes de futebol, os cafés, os bailes. E a evolução das suas escolas e modelos de ensino.

São Paulo era uma cidade que Gioconda aprenderia a conhecer a partir de um ponto de partida topográfico (a infância e a adolescência entre a Luz, o Bom Retiro e o Brás) e de um ponto de vista social e psicológico, que inclui a somatória dos olhares de uma rede familiar da qual ela própria mais tarde se destacaria, graças a uma trajetória singular, porém toda engendrada nas próprias possibilidades dessa mesma rede no seu cruzamento com a modernização urbana.

Gioconda é filha e neta de pequenos industriais emigrantes, que conviveram e ascenderam socialmente com "técnicas da Primeira Revolução Industrial: o bonde a burro, a iluminação a gás, manufaturas com trabalho manual, fábricas com energia a vapor” (Saes, 2004: 226). Mas é exatamente nessa condição que ela se inserirá num projeto político e ideológico que, à revelia dos seus mentores, permitirá a ela, e a outras e outros como ela, destinos diferentes dos que se esperaria. Nesse sentido, tendo transitado pelos entrelaçamentos contemporâneos da modernização conservadora implícita no projeto da “comunhão paulista", mas, também, pela periferia desse projeto, marcada pelo Modernismo e pelos seus reflexos culturais, literários, escolares e administrativos (do Departamento de Cultura à Sociedade de Etnografia e Folclore à Escola de Sociologia e Política), a trajetória de Gioconda será paradigmática em dois sentidos: o sentido próprio e o seu avesso - o paradoxal.

A mesma cidade reserva-lhe sofrimentos publicamente compartilhados (a penúria dos anos da Primeira Guerra Mundial, a gripe espanhola de 1918, as bombas de 1924 e os combates "revolucionários" de 1932), e outros mais íntimos e secretos. Também, contudo, abre-lhe as portas da Faculdade de Filosofia, encaminhando a sua trajetória para rumos não previstos. Aqui, já estamos na primeira metade daquela década de Trinta que (nunca será demasiado lembrá-lo) "foi um marco histórico, daqueles que fazem sentir novamente que houve um 'antes' diferente de um 'depois” (Candido, 2000: 181). Penso em Gioconda Mussolini, então, como alguém que também catalisou "elementos dispersos para dispô-los numa configuração nova" (Idem), assim como muitos dos seus colegas e das suas colegas companheiros e companheiras de geração, de classe e de origem étnica, que reencontraremos na Faculdade de Filosofia. 
Em 1935 Gioconda entra na então denominada Subseção de Ciências Sociais e Políticas da recém-criada Faculdade de Filosofia, Ciência e Letras da USP ${ }^{16}$, como parte da segunda turma de ingressantes naquela instituição e como "professora primária comissionada", ou seja, dispensada, com vencimentos, das suas atividades docentes, desempenhadas, como vimos, ora na pequena Jacupiranga ora no Grupo Escolar da Vila Prudente, mas sempre subordinadas à suas tarefas como aluna da Faculdade. Pertence àquele "grupo de jovens, animado de grande ardor para o trabalho, conhecendo perfeitamente as suas possibilidades, mas sabendo também que, antes de mais nada, são professores e que por esta razão foram enviados à Faculdade", na definição de um dos seus mais destacados professores, o geógrafo francês Pierre Monbeig (Limongi, 2011: 191).

Mulher, e com sobrenome ${ }^{17}$ imigrante, Gioconda Mussolini encaixa-se bem no perfil dos alunos da FFCL a partir do seu segundo ano de funcionamento, um grupo social muito diferente do preconizado pelos seus mentores, e também bem distinto do perfil daqueles que se encaminhavam para as antigas faculdades profissionais já existentes (Idem: 197): os filhos da elite paulista. Em depoimento, Antonio Candido narra, ainda, a existência de dois grupos, na Faculdade de Filosofia:

os rapazes e moças de famílias de classe média mais ou menos arranjada, em geral filhos de profissionais liberais, fazendeiros comerciantes, altos funcionários, que só estudavam e não trabalhavam. E havia os professores primários comissionados [...] dos quais sairiam alguns dos seus [da Faculdade] mais brilhantes professores (apud Freitas, 1993, p. 41).

E, em outra ocasião (Candido, 1980: 102):

[A Faculdade de Filosofia] era de fato uma iniciativa da cultura burguesa, como não podia deixar de ser; era a oligarquia pagando o luxo de construir uma Faculdade de tipo franco-italiano. Mas com isso [...] abriu as oportunidades para a formação moderna de um grupo no fundo inconformado em vários níveis. Grupo crescido no flanco da sociedade burguesa, constituído não apenas pelos seus rebentos mais inquietos ou francamente insatisfeitos, que recusavam o molde aristocratizante das escolas tradicionais, mas de elementos da pequena burguesia, professores primários comissionados [...].

Outro depoimento, de Maria Isaura Pereira de Queiroz (1999: 262), proporciona mais detalhes e apresenta um contexto em que é mais fácil situar a experiência de Gioconda Mussolini: 
todas as vezes que a quantidade de vagas não fosse preenchida [...] abrir-se-ia o exame para os professores normalistas que, exercendo sua profissão, quisessem melhorar de nível. Exigia-se que no exame de ingresso e naqueles que iriam prestar durante o curso obtivessem sempre nota igual ou superior a sete, caso contrário seriam remetidos de volta à escola ou ao ginásio em que trabalhavam. [...] Porém foram poucos os que persistiram e chegaram a se diplomar.

Finalmente, Jandyra França Barzaghi, aluna da primeira turma de química na FFCL (e primeira doutora nessa disciplina, em 1942), também lembra (apud Blay e Lang, 1984: 238):

Uma das finalidades da nova Faculdade [...] era formar professores primários, secundários, especialistas nas diversas matérias. [...] As professoras [comissionadas] acudiram em massa, espalharam-se por toda a Faculdade, primeiramente matriculadas em caráter condicional, logo depois convertida em matrícula regular, com aceitação do diploma de escola normal, desde que anterior a 1937; isto porque em 1936 tinha sido criado o Colégio Universitário e, daí por diante, nos anos seguintes, só os alunos que o cursavam teriam ingresso na Faculdade.

Essa pluralidade de origens dos alunos da FFCL continuaria durante alguns anos. Maria Isaura Pereira de Queiroz, pertencente a “uma família quatrocentona” (Queiroz, 1991: 14), cinco anos mais moça que Gioconda, mas que entraria na Faculdade só em 1946, ou seja, onze anos depois do ingresso dela, tendo sido, aliás, aluna e mais tarde colega da própria Gioconda, lembra também:

Adolescente, fiquei sabendo que não poderia freqüentar nem qualquer corso, nem qualquer baile. O corso "freqüentável era o da avenida Paulista, onde encontrava primos e primas, filhos de amigos da família - onde, em suma, permanecia no "meu meio". No bairro do Brás havia também um corso e famosas batalhas de confete; mas era impensável que meninas de "boa família" se misturassem com imigrantes italianos e espanhóis e seus descendentes! [...] No fim dos anos 30, o corso da avenida Paulista foi se tornando cada vez mais "misturado"; em muitos dos carros, havia gente que, pela maneira de se vestir e comportar, contrariava as regras da "nossa" classe social. A "promiscuidade" se tornava intolerável e as famílias da camada superior se retiravam pouco a pouco das ruas, deixando para o "povo" a celebração carnavalescas de desfiles.

Em outras palavras, aquela "promiscuidade", saindo da avenida Paulista, deslocava-se para as salas de aula da Faculdade. No entanto, a FFCL não possuía apenas uma diferenciação interna engendrada pelas origens sociais dos seus alunos, se prestarmos fé à reflexão memorialista de Miriam Moreira Leite (1994: 169): “Algumas das diferenças internas devem-se ao objetivo múltiplo de seus planejadores. A Faculdade de Filosofia seria uma 
unidade onde se institucionaria a ciência básica, onde os estudos lingüísticos seriam aprofundados e onde se desdobraria e se adequaria uma Pedagogia que formasse professores do ensino médio".

A FFCL começou a funcionar na Avenida Doutor Arnaldo, no Sumaré, juntamente com a também recém-criada Faculdade de Medicina e Cirurgia de São Paulo. Em 1938, as Ciências Humanas (e a Matemática) transferem-se para o terceiro andar daquele mesmo prédio do Instituto Caetano de Campos, na praça da República, onde Gioconda havia frequentado a Escola Normal. Finalmente, após mais algumas andanças pela cidade, em 1948, ocupará a sua sede histórica, na Rua Maria Antônia. É interessante atentar para o fato de que, no imaginário e na mitologia uspianas, e da FFCL em particular, ao que me parece, o local por excelência é o prédio da Maria Antônia, pouco ou quase nada restando para a memória "da Praça" (a Praça da República, como era metonimicamente chamado o Caetano de Campos). Oliveiros S. Ferreira, na sua colaboração a um dos livros que mais contribuíram no fortalecimento do mito da Maria Antônia, é um dos poucos a lembrar: "Não se pode falar da Maria Antônia sem falar da Praça. Uma continua a outra, sendo dela a transformação que destruirá o mito forjado no seio da comunidade construída no terceiro andar da Escola Normal "Caetano de Campos" (1988: 19). Ferreira teve trajetória semelhante à de Gioconda: no Caetano de Campos frequentara o ginásio, de forma que o ingresso na Faculdade coincidia com um regresso à Praça. Agora, no entanto, “a universidade era coisa séria para gente grande e [...] nela iriam pôr à prova o seu saber, que era pouco" (Idem: 20). Quando a Faculdade chega à Praça, em 1938, Gioconda já é auxiliar de ensino e o seu saber já havia sido posto à prova - e com sucesso - pelos professores franceses.

Maria Conceição Vicente de Carvalho, a primeira doutora em Geografia, no Brasil (orientada por Monbeig), importante referência para os trabalhos iniciais de Gioconda no litoral, também relembra:

[...] a primeira instalação [foi] nas salas da Faculdade de Medicina de São Paulo, de onde fomos violentamente expulsos, professores e alunos, debaixo de vaias dos alunos da medicina, de dentro das salas de aula até o portão de saída. Daí então a procura, as mudanças, que foram dos porões da casa de Macedo Soares na Rua da Consolação até o sótão do Palacete Street, da Alameda Glete; percorremos, depois, uma série de instalações, passando para o terceiro andar do Edifício da atual Secretaria de Educação, a Escola Caetano de Campos (Blay e Lang, 1984: 2140) ${ }^{18}$. 
Um depoimento mais circunstanciado da expulsão da FFCL do prédio da Doutor Arnaldo é de um antigo aluno de Medicina, testemunha dos fatos, e futuro reitor da USP nos seus anos mais dramáticos, Helio Lourenço de Oliveira:

Em alguns casos, partes de prédios oficiais eram-lhe [à FFCL] emprestados: isso ocorreu com o Departamento de Química, que veio a ocupar algumas salas disponíveis no $3^{\circ}$ andar do edifício da Faculdade de Medicina. Quando, pela chegada da nova turma de estudantes, se impôs a necessidade de aumentar o espaço ocupado, e para isso se iniciou a construção de novas salas sobre o terraço disponível para eventuais ampliações, explodiu a reação dos estudantes de medicina. [...] Os atos principais foram a demolição dos andaimes erguidos para aquela construção, seguida da interrupção das aulas [...] e convite aos respectivos professores e alunos para que se retirassem do prédio da Faculdade de Medicina (Oliveira, 1984: 210).

Também, é mais uma vez Maria Isaura Pereira de Queiroz a proporcionar um depoimento significativo:

A Faculdade de Filosofia, Ciências e Letras estava dispersa em vários pontos, sendo o principal a então bela Praça da República, onde departamentos como os de Filosofia, Ciências Sociais e Letras se aninhavam no terceiro andar o mais elevado - do Instituto Caetano de Campos. Este instituto possuía, nos dois primeiros andares, um jardim-de-infância, uma escola primária, um Ginásio e uma Escola Normal! Instituição conhecida e respeitada, nela tinham estudado minha mãe e minhas tias, tanto do lado materno como do lado paterno, e, em seguida, suas filhas (Queiroz, 1999: 261).

Gioconda Mussolini não poderia lembrar nada disso: ela é a primeira da sua família a continuar os estudos além da escola primária.

Ela assiste às aulas - ministradas sempre em francês ${ }^{19}$ - de alguns dos professores daquela que ficou conhecida como a "missão francesa" "20: Paul Arbousse Bastide e Claude Lévi-Strauss (Sociologia), Pierre Monbeig (Geografia) e Jean Magüé (Filosofia), entre outros. São seus colegas de turma Gilda de Mello e Souza (então Moraes Rocha), Mário Wagner Vieira da Cunha, Ruy Coelho, Décio de Almeida Prado e Egon Schaden. Este, procedente de uma família de origem alemã, de Santa Catarina, é destinado a desempenhar um papel de grande relevância na vida e na carreira de Gioconda.

Pouco se sabe sobre esse período de estudos. Antonio Candido menciona um episódio (presenciado, porém por sua mulher, Gilda de Melo e Souza ${ }^{21}$ ), envolvendo um mestre francês: o silêncio, demorado e constrangedor, de Gioconda, em pé, no meio da classe, numa sabatina do professor Lévi-Strauss à qual ela não consegue responder, 
paralisada pela angústia e pela humilhação. Curiosamente, o nome de Gioconda figura na conhecida listagem do antropólogo em Tristes Trópicos:

[...] Pensando em vós, segundo vosso costume, por vossos nomes de batismo tão barrocos para um ouvido europeu, mas cuja diversidade exprime o privilégio que foi ainda o de vossos pais, de poder livremente, de todas as flores de uma humanidade milenar, colher o viçoso buquê da vossa: Anita, Corina, Zenaida [sic], Lavínia, Thaís, Gioconda, Gilda, Oneide, Lucilla, Zenith, Cecília, e vós, Egon, Mário Wagner, Nicanor, Ruy, Lívio, James, Azor, Achilles, Décio, Euclides, Milton [...] (Lévi-Strauss, 1996: 99-100).

Alguns desses nomes desapareceram da história das Ciências Sociais brasileiras, outros acompanharão por inteiro a trajetória pessoal e acadêmica de Gioconda, outros, ainda, foram colaterais - testemunhas, de alguma forma, de opções diferentes, mas solidárias.

Gilda de Mello e Souza, Ruy Coelho e Décio de Almeida Prado (filho do então diretor da Faculdade, Antonio de Almeida Prado), juntamente com Lourival Gomes Machado (também colega de Gioconda no Curso de Ciências Sociais - sairá formado em 1938, mas não é citado por Lévi-Strauss), Antonio Candido (que entraria no curso em 1939, quando Lévi-Strauss já voltara para a França e Gioconda já estava trabalhando na Cadeira de Sociologia I) e Paulo Emilio Salles Gomes (aluno da Faculdade desde 1939, após um ano e meio de prisão em São Paulo e dois anos de exílio em Paris), formariam o núcleo mais expressivo e atuante da revista $\left(\right.$ e do grupo ${ }^{22}$ ) Clima. Dessa revista, que circulou entre 1941 e 1944, Gioconda só pode ter sido leitora interessada, e colega, algo distanciada, dos seus mentores. Assim como, mais tarde, aconteceria com Florestan Fernandes (que ingressaria na Faculdade em 1941), tratava-se de medir e administrar as distâncias com moços de um círculo socialmente, simbolicamente e culturalmente mais capitalizado, que lhes permitia, inclusive, um acesso, há mais tempo consolidado, a bibliotecas familiares bem abastecidas de obras em várias línguas, vivas e mortas. Numa gangorra de aproximações e distanciamentos, de atração e relutância, devem ter transcorrido as relações entre Gioconda Mussolini e alguns dos seus colegas. Mário Wagner Vieira da Cunha desabafa, defendendo a posição dos alunos oriundos - como ele - do meio normalista:

[...] houve momentos nas aulas de sociologia e filosofia [em] que a coisa era irritante, porque havia os alunos oficiais, matriculados, que faziam os trabalhos, se esforçavam humildemente, e havia os alunos snobs, que vinham com os grandes chapéus e vestidos muito bonitos, assistiam às aulas, conversavam com os professores, convidavam para um chá e a sociologia ficava um salão literário 
muito importante e uma sala de aula. E nós, sempre num cantinho, empurrados dessa forma (Pinheiro Filho e Miceli, 2008).

Entretanto, Antonio Candido esclarece o que, também, estava se desenrolando entre todos eles, marcando, já, locais de referência e destinos acadêmicos:

Nós pertencemos a uma fase heróica da Faculdade, que foi a implantação dos cursos pelos professores estrangeiros. Era o começo daquele tipo de estudos, havia ainda muito diletantismo, nós transitávamos da arte para a filosofia, da sociologia para a literatura. Mas ao nosso lado havia rapazes e moças que já se orientavam pelas exigências da especialização. Penso em gente como Lucila Herrmann, Gioconda Mussolini, Dorival Teixeira Vieira, José Francisco de Camargo, Eduardo d'Oliveira França, Egon Schaden e outros, alguns dos quais professores primários comissionados (Pontes, 2001: 18) ${ }^{23}$.

As duas vertentes, entretanto, praticavam por caminhos diversos, mas não divergentes, aquilo que o autor de Os parceiros do rio Bonito, nessa mesma entrevista de 1987, definira certeiramente para a geração anterior à deles: “O Brasil começou a se apalpar” (Idem: 6), entre diletantismo e crítica, de um lado, e especialização e sociologia, por outro.

Terminados os três anos de bacharelado, o último dos quais se desdobraria no Curso de Didática da própria Faculdade de Filosofia, que permitia aos bacharéis se tornarem também licenciados, Gioconda (portanto em 1937) se torna aluna do Instituto de Educação da USP, justamente às vésperas do seu fechamento por parte do governo paulista (sob a intervenção de Adhemar de Barros) (Bontempi Jr., 2007). O Ieusp, na realidade, teve os seus professores efetivos transferidos para a própria FFCL.

Esse intercruzamento de nomes, instituições, artigos e temas de pesquisa permite, agora, atestar que, ao longo dos anos Trinta e na primeira metade da década de Quarenta, Gioconda Mussolini, imediatamente antes, durante e logo depois da sua permanência como aluna da Subseção de Ciências Sociais e Políticas da Faculdade de Filosofia da UsP, envolve-se em um campo novo e peculiar, formado por docentes, pesquisadores, saberes, atuações e sugestões teóricas e metodológicas, com uma agenda científica que está sendo definida e cumprida num espaço que inclui a mesma FFCL, a Escola Livre de Sociologia e Política, o Departamento Municipal de Cultura e a Sociedade de Etnografia e Folclore. Participam desse campo algumas figuras decisivas nesses momentos inaugurais e mesmo no destino das Ciências Sociais em São Paulo e no Brasil - e, evidentemente, no começo de carreira e no destino individual de Gioconda Mussolini. São anos em que ela recebe a forte influência dos estudos de sociologia e antropologia urbana; ao mesmo tempo em que está 
em contato com a forte âncora metodológica constituída pela ciência estatística: ambas as perspectivas em fase de implantação e fortalecimento na ELSP. São anos em que o tema da pobreza e das classes populares, nas múltiplas e integradas perspectivas econômica, cultural e social, afirma-se como questão prioritária tanto para as esferas administrativas e políticas paulistas (com os ardilosos reflexos ideológicos que não há espaço para abordar aqui), quanto para os cientistas sociais envolvidos nessas várias instituições, quanto para a orientação pessoal de Gioconda, que dirigirá e transferirá essas preocupações para um setor até então quase desabitado, malíssimo frequentado pelos cientistas sociais ativos no Brasil (com a exceção de alguns geógrafos): o das populações de pescadores do litoral de São Paulo.

Em suma, de 1934 a 1945, Gioconda Mussolini recebe o treinamento necessário ao conjunto de atividades que ela irá desenvolver autônoma e individualmente a partir de meados dos anos Quarenta ${ }^{24}$ : um treinamento que se desdobra em teorias e práticas, em participação direta em investigações sociais de grande relevância, na aquisição dos instrumentos metodológicos e do desenvolvimento da reflexão teórica necessária à formação de uma cientista social moderna. Cabe enfatizar, nessa perspectiva, que esse espaço de formação, em que a participação em atividades práticas e a reflexão teórica e metodológica parecem bem equilibradas, ocupa justamente essa gama variada de instituições (FFCL, ELSP, Departamento de Cultura e SEF), de forma que, mais que uma divisão de trabalho entre tendências diferenciadas, parece delinear-se, aqui, um quadro de compartilhamentos, solidariedades e remissões.

\footnotetext{
${ }^{1}$ Muitas informações biográficas sobre Gioconda são retiradas de um Curriculum Vitae redigido por ela, em 1965, e conservado numa pasta de processos do protocolo da Fflch/USP e de várias conversas realizadas com Dona Ariclé Plessmann, sua irmã, entre 2006 e 2008.

${ }^{2}$ Livro 003, página 055.

${ }^{3}$ Cf., sobretudo, Trento (1989: 139-156) e as suas numerosas referências, e Lima (1954).

${ }^{4}$ Informação contida no seu Curriculum de 1965.

${ }^{5}$ Disponível em:

www.itaucultural.org.br/aplicexternas/enciclopedia_ic/index.cfm?fuseaction=instituicoes_texto\&cd_verbete $=5397$. Acesso em 10/03/2015.

${ }^{6}$ Disponível em: http://www.crmariocovas.sp.gov.br/pdf/neh/1897-1903/1898-

Terceiro_Grupo_Escolar_do_Braz.pdf. Acesso em 10 de março de 2015.
} 
${ }^{7}$ Disponível em: http://www.crmariocovas.sp.gov.br/mor_l.php?t=04. Acesso em 10 de março de 2015.

8 Fernando de Azevedo (1894-1974), personagem que reencontraremos inúmeras vezes na trajetória de Gioconda Mussolini, fora, em 1932, um dos mentores e o principal redator do "Manifesto dos Pioneiros da Educação Nova”. Neste ano de 1933, ele é Diretor do Ensino Público Paulista, e nessa posição é o autor do "Código de Educação" que dá vida ao novo Instituto. Logo em seguida, como é por demais sabido, estará na linha de frente do grupo dos mentores e criadores da USP.

${ }^{9}$ Em 1938, o Ieusp foi extinto. Boa parte das suas atividades e a grande maioria dos seus quadros docentes foi transferida para a Faculdade de Filosofia, Ciências e Letras, formando ali a nova Seção de Educação (depois de Pedagogia). Cf. Bontempi Jr. (2007).

${ }^{10}$ Roldão Lopes de Barros (1884-1951), formado em Direito no Largo de São Francisco, foi também diretor da Escola Normal Padre Anchieta.

11 Noemy Marques da Silveira (1902-1980) casou nesse ano de 1933 com o engenheiro tcheco Bruno Rudolfer, que viria a ser professor de Gioconda no Mestrado da Escola Livre de Sociologia e Política, nos anos Quarenta. Esse casamento, e o fato de ela ter sido a primeira mulher titular de uma Cátedra Universitária em São Paulo, a torna uma figura especial na trajetória de Gioconda Mussolini.

12 Trata-se do mesmo Hermes Lima (1902-1978) que se tornaria primeiro-ministro de João Goulart e presidente do Supremo Tribunal Federal.

13 Autor, nesse ano de 1933, de um dos primeiros manuais de Sociologia para o ensino médio, as Lições de Sociologia (Melhoramentos). Cf. Meucci (2001).

${ }^{14}$ É esta a denominação tomada, a partir de 1931, pelo antigo Instituto de Higiene de São Paulo. Cf. Candeias (1988).

15 Aliás, um aluno de Gioconda Mussolini.

16 A literatura relativa à criação da FFCL, ao seu contexto político, histórico e cultural, assim como aos primeiros anos do seu funcionamento, seus mentores, alunos e professores já é muito ampla. Seleciono, para uma primeira abordagem, os trabalhos de Cardoso (1982), e de Miceli (2001b), Limongi (2001), Peixoto (2001), contidos nos dois volumes da História das ciências sociais no Brasil, organizada por Sergio Miceli; e o livro de Heloísa Pontes (1998). Já os dados relativos à carreira acadêmica de Gioconda Mussolini estão, parcialmente, em Arantes (1989) e, sobretudo, no mencionado Curriculum de 1965.

17 A essa altura (1935), um sobrenome já muito "sonoro": Benito Mussolini conquistara o poder na Itália em 1922, assumindo-o ditatorialmente em 1924, e ainda é aliado de Getúlio Vargas. Como se sabe, a ruptura entre o Brasil e os países do eixo só se daria na virada entre 1941 e 1942.

${ }^{18}$ Mas o que funcionou no Palacete Street foram as cadeiras e as disciplinas de História Natural e de Química, obrigatórias para os estudantes de Ciências Sociais.

${ }^{19}$ Gilda de Mello e Souza, que foi colega de Gioconda do primeiro ao último dia do curso, lembra (em Blay e Lang, 1984: 2139): "Eu, por exemplo, nunca tive uma aula que não fosse em francês".

20 Trata-se também de um aspecto hoje amplamente descrito e analisado. Cf., pelo menos, Peixoto (2001), Lefevbre (1990) e o depoimento de Antonio Candido em Pontes (2001).

${ }^{21}$ Em entrevista; novembro de 2005. Na ocasião, a professora Gilda já se encontrava gravemente acometida pela doença que seria causa da sua morte, ocorrida menos de dois meses depois do meu encontro com o professor Antonio Candido.

${ }^{22}$ Cf. Pontes (1998).

${ }^{23}$ Dorival Teixeira Vieira seria mais tarde professor catedrático na Faculdade de Economia e Administração; 
José Francisco de Camargo seria $2^{\circ}$ assistente de Fernando de Azevedo na Cadeira de Sociologia Educacional (em 1942) e $1^{\circ}$ assistente do prof. Paul Hugon na Cadeira de Economia Política e História das Doutrinas Econômicas (1946) e, finalmente, também catedrático e Diretor da FEA; Eduardo d'Oliveira França foi discípulo de Fernand Braudel, assistente de Eurípides Simões e, em seguida, catedrático de História Moderna e Contemporânea.

${ }^{24}$ Embora, como vimos (Ciacchi, 2007a), ela continue, ao longo da segunda metade da década, colaborando com pesquisas e levantamentos coordenados por seus mestres e ou chefes diretos, como Roger Bastide e Emilio Willems, fazendo jus ao sentido literal dos cargos que ela ocupará na FFCL: auxiliar e assistente.

\section{Referências bibliográficas}

ALviM, Zuleika M.F.

1986 Brava gente! Os italianos em São Paulo 1870-1920. São Paulo, Brasiliense.

AMERicANO, Jorge

2004 São Paulo naquele tempo (1895-1915). $2^{\mathrm{a}}$ ed. São Paulo, Carrenho Editorial, Narrativa Um, Carbono 14.

Arantes, Antonio Augusto

1989 “20 anos da morte de Gioconda Mussolini”. Boletim da ABA, n 7: 8.

Blay, Eva e LANG, Alice Gordo

1984 “A mulher nos primeiros tempos da Universidade de São Paulo”. Ciência e Cultura, vol. 36, n. 12.

BONTEMPI JÚNIOR, B.

2007 “A incorporação do Instituto de Educação pela FFCL-USP: hipóteses para entender um campo cindido". Anped: 30 anos de pesquisa e compromisso social [Anais].

Rio de Janeiro: Anped, p. 1-15.

CANDEIAS, Nelly Martins Ferreira

1988 "Evolução histórica da educação em saúde como disciplina de ensino na Faculdade de Saúde Pública da Universidade de São Paulo - 1925 a 1967”. Revista de Saúde Pública, vol. 22, n. 4: 347-365.

CANDIDO, Antonio

1980 "Feitos da burguesia". In Teresina etc. Rio de Janeiro, Paz e Terra, pp. 95-106.

2000 A educação pela noite \& outros ensaios. São Paulo, Ática. 
CARDOSO, Irene

1982 A universidade da comunhão paulista. São Paulo, Autores Associados/Cortez.

CARone, Edgard

1972 A República Velba. São Paulo, Difel.

Cenni, Franco

1975 Italianos no Brasil, $2^{a}$ ed. fac-similar comemorativa, São Paulo, Martins/Edusp.

CIACCHI, Andrea

2007a "A mulher que puxou a rede. Gioconda Mussolini e os estudos sobre pesca no Brasil”. VII Reunião de Antropologia do Mercosul. CD-ROM.

2007b "Gioconda Mussolini: uma travessia bibliográfica". Revista de Antropologia, vol. 50, n. 1: 181-223.

2015 "Mestrança: Gioconda Mussolini e a Antropologia em São Paulo (19381969)". Tempos Históricos, vol. 19: 153-186.

COHEN, Ilka Stern

2006 Bombas sobre São Paulo. São Paulo, Unesp.

DEAN, Warren

1975 "Industrialização Durante a República Velha". In FAusto, Boris (org.), História geral da civilização brasileira. Tomo III, "O Brasil Republicano", São Paulo, Difel, pp. 251-283.

EVANGELISTA, Olinda

2002 A formação universitária do professor: o Instituto de Educação da Universidade de São Paulo (1934-1938). Florianópolis, NUP, CED, UFSC, Cidade Futura.

FÁvero, Maria de Lourdes A. e BritTo, Jader M. (orgs.)

2002 Dicionário de Educadores do Brasil. Rio de Janeiro, Editora da UFRJ.

FERreIra, Oliveiros S.

1988 “Maria Antônia começou na Praça”. In SANTos, Maria Cecília Loschiavo dos (org.). Maria Antônia: uma rua na contramão. São Paulo, Nobel, pp. 19-26.

FreitAs, Sônia Maria de

1993 Reminiscências. São Paulo, Maltese.

GANDINI, Raquel

2010 Almeida Júnior. Recife, Massangana. 
HuTTER, Lucy Maffei

1972 A Imigração Italiana em São Paulo (1880 - 1890). São Paulo, Instituto de Estudos Brasileiros/UsP.

LEFEBVRE, Jean-Paul

1990 "Les professeurs français des missions universitaires au Brésil (1934-1944)". Cabiers du Brésil contemporain, n.12: 89-100.

LEITE, Miriam Lifchitz Moreira

1994 “Memória da Faculdade de Filosofia (1934-1994)”. Estudos Avançados, vol. 8, n. 22: $167-177$.

LÉVI-STRAuss, Claude

1996 Tristes Trópicos. São Paulo, Companhia das Letras.

LIMA, Heitor Ferreira

1954 Evolução Industrial de São Paulo. São Paulo, Livraria Martins Editora.

LIMONGI, Fernando

2001 “A Escola Livre de Sociologia e Política em São Paulo”. In MiCELI, S. (org.). História das Ciências Sociais no Brasil. Vol. 1. II ed. São Paulo, Vértice, pp. 257-275.

MARTINS, José de Souza

1981 "Empresários e trabalhadores de origem italiana no desenvolvimento industrial brasileiro entre 1880 e 1914". Dados (Revista de Ciências Sociais), vol. 24, n. 2: $237-264$.

MeuccI, Simone

2001 "Os primeiros manuais didáticos de Sociologia". Estudos de Sociologia, v. 6, n. 10: 121-158.

MiCELI, Sergio (org.)

2001a História das ciências sociais no Brasil, vol. 1. São Paulo, Vértice.

2001b "Condicionantes do desenvolvimento das ciências sociais". In

(org.), História das ciências sociais no Brasil, vol. 1. São Paulo, Vértice, pp. 72-110.

MORSE, Richard M.

1970 Formação histórica de São Paulo. Da comunidade à metrópole. São Paulo, Difel.

MотA, Carlos Guilherme

2003 “São Paulo: exercício de memória”. Estudos avançados, v. 17, n.48: 241-263. 
Mussolini, Gioconda

(s.d.) Documentos de Gioconda Mussolini. Arquivos da Seção de Protocolo. Administração da Fflch-USP.

NAGLE, Jorge

1974 Educaşão e sociedade na Primeira República, São Paulo, EPU/Rio de Janeiro, Fename.

Oliveira, Helio Lourenço de 1984 “USP - 50 anos”. Ciência e Cultura, vol. 36, n. 12: 2109-2112.

PeIXoto, Fernanda

2001 "Franceses e norte-americanos nas ciências sociais brasileiras (1930-1960)". In MiCELI, Sergio (org.). História das ciências sociais no Brasil. São Paulo, Vértice, pp. 477-532.

Pinheiro Filho, Fernando Antonio e Miceli, Sergio

2008 "Entrevista com Mário Wagner Vieira da Cunha”. Tempo social, São Paulo, v. 20, n. 2: 259-301.

PONTES, Heloísa

1998 Destinos Mistos; os críticos do Grupo Clima em São Paulo - 1940-1968. São Paulo, Companhia das Letras.

2001 “Entrevista com Antonio Candido”. Revista Brasileira de Ciências Sociais, vol. 16, n. 47: 5-30.

QueIroz, Maria Isaura Pereira de 1991 "Prólogo". In Carnaval Brasileiro. São Paulo, Brasiliense, pp. 11-25. 1999 "Reminiscências". In Aguiar, Flávio (org.), Antonio Candido: pensamento e militância. São Paulo, Editora Fundação Perseu Abramo; Humanitas/Fflch/usP, pp. 261-266.

SAES, Flavio

2004 “São Paulo Republicana: vida econômica". In PORTA, Paula (org.), História da Cidade de São Paulo. Vol. 3: A cidade na primeira metade do século Xx. São Paulo, Paz e Terra, pp. 215-257.

Trento, Angelo

1989 Do outro lado do Atlântico. Um Século de Imigração Italiana no Brasil. São Paulo, Nobel. 


\title{
Landing from ship, boarding the canoe: Gioconda Mussolini, 1886-1938
}

\begin{abstract}
The main objective of this paper is the reconstruction of a specific aspect of biographical and intellectual career of Gioconda Mussolini, who was, successively, undergraduate student, assistant and professor at the Faculty of Philosophy, Sciences and Letters (FFCL) of the University of São Paulo from 1935 to 1969: her school journey, from childhood to degree in FFCL. I propose, however, to go even further in time and space, in order to include in this trajectory the arrival of her father's family from Italy, in 1886, and her school experience in the city of São Paulo, in the twenties and thirties of last century. My hypothesis is that this course is largely determined by her belonging to a special portion of the "Italian-paulistan" experience in the early twentieth century, on the one hand, and on the other, that it determines her intelectual option to the Social Sciences and Anthropology.
\end{abstract}

KEYWORDS: Gioconda Mussolini, Brazilian Anthropology, Antropologia brasileira, Intellectual careers, Instituto de Educação "Caetano de Campos", Faculty of Philosophy, Sciences and Letters (FFCL) of the University of São Paulo, Italian immigration to São Paulo.

Recebido em abril de 2015. Aceito em agosto de 2015. 